\title{
Prolongation of Evoked and Spontaneous Synaptic Currents at the Neuromuscular Junction after Activity Blockade Is Caused by the Upregulation of Fetal Acetylcholine Receptors
}

\author{
Xueyong Wang, ${ }^{1}$ Kathrin L. Engisch, ${ }^{1}$ Russell W. Teichert, ${ }^{2}$ Baldomero M. Olivera, ${ }^{2}$ Martin J. Pinter, ${ }^{3}$ and Mark M. Rich ${ }^{1}$ \\ ${ }^{1}$ Department of Neuroscience, Cell Biology, and Physiology, Wright State University, Dayton, Ohio 45435, ${ }^{2}$ Department of Biology, University of Utah, Salt \\ Lake City, Utah 84112, and 'BDepartment of Physiology, Emory University School of Medicine, Atlanta, Georgia 30322
}

\begin{abstract}
It has been shown previously in a number of systems that after an extended block of activity, synaptic strength is increased. We found that an extended block of synaptic activity at the mouse neuromuscular junction, using a tetrodotoxin cuff in vivo, increased synaptic strength by prolonging the evoked endplate current (EPC) decay. Prolongation of EPC decay was accompanied by only modest prolongation of spontaneous miniature EPC (MEPC) decay. Prolongation of EPC decay was reversed when quantal content was lowered by reducing extracellular calcium. These findings suggested that the cause of EPC prolongation was presynaptic in origin. However, when we acutely inhibited fetal-type acetylcholine receptors (AChRs) using a novel peptide toxin ( $\alpha \mathrm{A}$-conotoxin OIVA[K15N]), prolongation of both EPC and MEPC decay were reversed. We also blocked synaptic activity in a mutant strain of mice in which persistent muscle activity prevents upregulation of fetal-type AChRs. In these mice, there was no prolongation of EPC decay. We conclude that upregulation of fetal-type AChRs after blocking synaptic activity causes modest prolongation of MEPC decay that is accompanied by much greater prolongation of EPC decay. This might occur if acetylcholine escapes from endplates and binds to extrajunctional fetal-type AChRs only during large, evoked EPCs. Our study is the first to demonstrate a functional role for upregulation of extrajunctional AChRs.
\end{abstract}

Key words: neurotransmitter; synaptic; plasticity; activity; extrajunctional; acetylcholine receptors; transmission; homeostatic; endplate; TTX

\section{Introduction}

The ways in which activity regulates the function of the nervous system have been studied extensively but are still only partially understood. It has recently been proposed that chronic manipulations of activity trigger a series of changes in synaptic function that maintain firing rates of networks within certain boundaries; thus, this has been termed homeostatic regulation of synaptic function (Turrigiano and Nelson, 2004; Davis, 2006). Increases in the number of neurotransmitter receptors on the postsynaptic cell appear to contribute to homeostatic increases in synaptic strength (O'Brien et al., 1998; Turrigiano et al., 1998; Wierenga et al., 2005).

The mammalian neuromuscular junction (NMJ) is a classic synaptic preparation ideally suited for studies of synaptic function in vivo, because there is one presynaptic input and one neurotransmitter. In normal, innervated adult muscle, only one isoform of acetylcholine receptor (AChR) is expressed that contains the $\alpha(2), \beta, \delta$, and $\varepsilon$ subunits (Steinbach, 1989). In these muscles, AChRs are located almost exclusively within NMJs; very few AChRs are present on muscle membrane outside of the endplate

Received June 13, 2006; revised July 21, 2006; accepted July 22, 2006.

This work was supported by National Institutes of Health Grant P01 NS 40405 (M.M.R.). We thank Doju Yoshikami for helpful comments and the Jean Rivier laboratory for synthesis of $\alpha$ A-conotoxin OIVA[K15N].

Correspondence should be addressed to Dr. Mark M. Rich, Room 014, M \& M Building, Wright State University, 3640 Colonel Glenn, Dayton, $0 H$ 45435. E-mail: mark.rich@wright.edu.

DOI:10.1523/JNEUROSCI.2493-06.2006

Copyright $\odot 2006$ Society for Neuroscience $\quad$ 0270-6474/06/268983-05\$15.00/0
(Hartzell and Fambrough, 1972; Lomo and Rosenthal, 1972). An extended blockade of neuromuscular activity triggers what appears to be a homeostatic increase in postsynaptic expression of AChRs (Hartzell and Fambrough, 1972; Lomo and Rosenthal, 1972; Lomo and Westgaard, 1975). These upregulated AChRs are of a different type than the AChRs normally present in mature muscle and contain the $\alpha(2), \beta, \delta$, and $\gamma$ subunits (fetal-type AChRs) (Witzemann et al., 1987; Kues et al., 1995). The functional impact of upregulation of fetal-type AChRs has been unclear because they are primarily located in the extrajunctional muscle membrane after block of muscle activity (Kues et al., 1995). In the current study, we found that an extended block of activity at the mouse NMJ in vivo increases synaptic charge because of prolongation of endplate current (EPC) decay. Our data provide evidence that the prolongation of EPC decay is caused by upregulation of extrajunctional fetal-type AChRs.

\section{Materials and Methods}

Tetrodotoxin (TTX) cuff placement on the left sciatic nerve was performed under intraperitoneal anesthesia (chloral hydrate, $0.6 \mathrm{~g} / \mathrm{kg}$ ). TTX cuffs were fashioned from SILASTIC tubing and were connected to an Alzet osmotic pump (model 1002; Durect, Cupertino, CA) containing $850 \mu \mathrm{M}$ TTX (Alomone Labs, Jerusalem, Israel) dissolved in $0.9 \% \mathrm{NaCl}$. Two- to 4-month-old mice were used for experiments and killed using $\mathrm{CO}_{2}$ inhalation, and their tibialis anterior muscles were removed. All animal surgery was performed in accordance with Wright State Laboratory Animal Care and Use Committee guidelines.

The recording chamber was perfused continuously with Ringer's so- 
Table 1. Prolongation of EPC decay after an extended block of synaptic activity is attributable to the upregulation of fetal-type AChRs

\begin{tabular}{|c|c|c|c|c|c|}
\hline & EPC amplitude (nA) & EPC integral $(n A \cdot m s)$ & EPC decay (ms) & MEPC decay (ms) & $n$ \\
\hline Control & $73.7 \pm 5.2$ & $172.1 \pm 11.6$ & $1.80 \pm 0.05$ & $1.24 \pm 0.03$ & 9 muscles \\
\hline Activity blocked & $79.2 \pm 7.1$ & $323.2 \pm 38.0^{*}$ & $3.18 \pm 0.28^{*}$ & $1.42 \pm 0.07^{* * *}$ & 6 muscles \\
\hline Control pre- $\alpha \mathrm{A}-0 \mathrm{IVA}[\mathrm{K} 15 \mathrm{~N}]$ & $101.1 \pm 6.4$ & $185.0 \pm 13.0$ & $1.40 \pm 0.05$ & $1.13 \pm 0.05$ & 8 fibers \\
\hline Control post- $\alpha$ A-0IVA[K15N] & $101.5 \pm 10.1$ & $186.5 \pm 20.7$ & $1.32 \pm 0.03$ & $1.08 \pm 0.02$ & 8 fibers \\
\hline Activity blocked pre- $\alpha$ A-0IVA[K15N] & $120.3 \pm 10.9$ & $445.8 \pm 38.8$ & $2.99 \pm 0.19$ & $1.59 \pm 0.06$ & 6 fibers \\
\hline Activity blocked post- $\alpha$ A-0IVA[K15N] & $97.2 \pm 8.0$ & $203.8 \pm 20.9^{* *}$ & $1.62 \pm 0.09^{* *}$ & $1.06 \pm 0.05^{* *}$ & 6 fibers \\
\hline $\mathrm{ClC}$ & $90.0 \pm 5.0$ & $236.0 \pm 10.4$ & $2.04 \pm 0.06$ & $1.32 \pm 0.05$ & 7 muscles \\
\hline CIC, activity blocked & $77.8 \pm 3.1$ & $217.3 \pm 7.2$ & $2.14 \pm 0.14$ & $1.31 \pm 0.04$ & 7 muscles \\
\hline
\end{tabular}

The top two and last two rows present data from multiple experiments on the effect of block of activity on EPCs and MEPCs. In these rows, $n$ is the number of muscles studied (in each muscle at least six muscle fibers were studied). Statistical comparisons in these cases were done using nested ANOVA $\left({ }^{*} p<0.01\right.$ vs control; ${ }^{* * *} p<0.05$ vs control). There were no statistically significant differences between $\mathrm{IIC}$ and CIC endplates in which nerve activity was blocked. The third through sixth rows represent data from smaller samples of control and activity blocked endplates studied before and after $\alpha \mathrm{A}$-conotoxin 0IVA[K15N]. For studies of $\alpha \mathrm{A}$-conotoxin 0IVA[K15N], $n$ is the number of muscle fibers studied, and statistical comparisons were made using a paired Student's $t$ test before and after toxin $\left({ }^{* *} p<0.01\right.$ vs pre- $\alpha$ A-conotoxin 0IVA[K15N]). CIC, CIC-1 chloride channel null mice.

lution containing the following (in mmol/l): $118 \mathrm{NaCl}, 3.5 \mathrm{KCl}, 2 \mathrm{CaCl}_{2}$, $0.7 \mathrm{MgSO}_{4}, 26.2 \mathrm{NaHCO}_{3}, 1.7 \mathrm{NaH}_{2} \mathrm{PO}_{4}$, and 5.5 glucose, at a temperature of $20-22^{\circ} \mathrm{C}$ and equilibrated with $95 \% \mathrm{O}_{2} / 5 \% \mathrm{CO}_{2}$ to maintain a $\mathrm{pH}$ of 7.3-7.4. In recordings performed in Ringer's solution containing low calcium/high magnesium, the same solution was used except that $\mathrm{CaCl}_{2}$ was reduced to $1 \mathrm{mmol} / \mathrm{l}$ and $\mathrm{MgSO}_{4}$ was increased to $8 \mathrm{mmol} / \mathrm{l}$. Endplate recordings were performed as described previously (Wang et al., 2004, 2005). Briefly, all endplates were stained with $10 \quad \mu \mathrm{M}$ 4-(4diethylaminostyryl)- $N$-methylpyridinium iodide (Magrassi et al., 1987), impaled with two electrodes within $100 \mu \mathrm{m}$ of the endplate, and voltage clamped to $-45 \mathrm{mV}$. Muscle fibers were crushed away from the endplate band to avoid movement induced by nerve stimulation (Glavinovic, 1979).

Determination of the contribution of fetal-type AChRs to EPCs and miniature EPCs (MEPCs) was performed by measuring EPCs and MEPCs in individual muscles before and after application $\alpha \mathrm{A}$-conotoxin OIVA[K15N] [synthesized as described previously (Teichert et al., 2005, 2006)]. After recording from endplates in control Ringer's solution, $\alpha \mathrm{A}$ conotoxin OIVA[K15N] was added to $20 \mathrm{ml}$ of Ringer's solution at a final concentration of $1 \mu \mathrm{M}$, and this solution was bubbled continuously with $95 \% \mathrm{O}_{2} / 5 \% \mathrm{CO}_{2}$ and recirculated throughout the bath. Endplates were relocated and reimpaled, and EPCs and MEPCs were recorded in the presence of $\alpha \mathrm{A}$-conotoxin OIVA[K15N]. Results from both the control and the activity-blocked endplates in these small samples differ somewhat from the larger samples presented in rows one and two of Table 1.

$C l C n 1^{\text {adr-mto2J }}$ mice were obtained from The Jackson Laboratory (Bar Harbor, ME), and a breeding colony was established. Mice homozygous for the $\mathrm{ClC}$ null mutation were identified by their inability to rapidly right themselves after being turned on their backs at 2 weeks of age. Unaffected littermates, consisting of mice that were heterozygous for the $\mathrm{ClC}$ mutation and mice that carried no copy of the mutation, were used for all of the other experiments.

Data on the effect of TTX cuffs in wild-type and ClC mice versus controls were tested for group differences using nested ANOVA (Neter et al., 1990). The $n$ for these data refers to the number of animals studied. Data on the effects of $\alpha \mathrm{A}$-conotoxin OIVA[K15N] compared the responses of a given endplate with and without toxin using the paired Student's $t$ test. The $n$ for these data refers to the number of endplates studied. Bonferroni's correction was used in all cases in which multiple comparisons were made. Mean values \pm 1 SEM are shown. Statistically significant differences were defined by a $p$ value $<0.05$.

\section{Results}

We measured currents at endplates in which evoked transmitter release was blocked by a TTX cuff on the nerve for 7-10 $\mathrm{d}$ and at control endplates that were untreated. Our use of the crushed muscle fiber preparation permitted measurement of EPCs at normal $\mathrm{Ca}^{2+}(2 \mathrm{mM})$ concentrations. Under these recording conditions, the peak amplitude of the EPC was the same for both control and TTX-cuff preparations (Fig. $1 A, B$; Table 1) ( $p=0.55$ ). However, there was an $88 \%$ increase in EPC integral in the TTXcuff preparations (Fig. $1 A, C$; Table 1$)(p<0.01)$ primarily because of the prolongation of EPC decay (Table 1). Placement of a
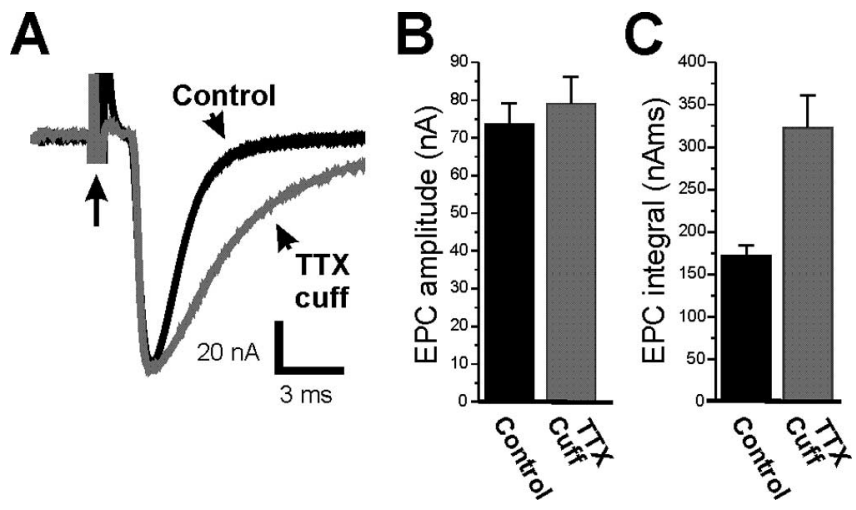

Figure 1. Extended blockade of neuromuscular activity increases synaptic strength because of the prolongation of the EPC. $\boldsymbol{A}$, Superimposed EPCs from a control endplate (black) and an endplate in which synaptic activity was blocked by a TTX cuff for $8 \mathrm{~d}$ (gray). Although the peak amplitude of the EPC is similar, there is prolongation of EPC decay after block of activity. Each EPC is preceded by a stimulus artifact (arrow with long tail). $\boldsymbol{B}$, Mean EPC amplitude in control endplates (black) and endplates in which activity was blocked for 7-10 d (gray). There is no statistically significant increase in EPC amplitude after block of synaptic activity ( $p=0.55)$. C, Mean EPC integral in control endplates (black) and endplates in which activity was blocked for 7-10 d (gray). There is a statistically significant increase in total charge carried by the EPCs after blocking synaptic activity $(p<0.01) . n=9$ control muscles and 6 muscles in which activity was blocked. Error bars represent the SEM.

saline cuff did not prolong EPC decay relative to control (1.83 \pm $0.07 \mathrm{~ms}$ vs $1.80 \pm 0.05 \mathrm{~ms}$ in control; $p=0.71 ; n=3$ muscles).

To better understand the mechanism underlying prolongation of EPC decay, we examined the effect of an extended block of synaptic activity on MEPC decay. MEPC decay was slightly prolonged after block of synaptic activity using a TTX cuff (Table 1) $(p<0.05)$. However, when all of the data were averaged, there was a prolongation of only $0.18 \mathrm{~ms}$ in the average MEPC decay in the same endplates that had a prolongation of $1.38 \mathrm{~ms}$ in the EPC decay (Table 1). We plotted EPC decay against MEPC decay in control endplates and endplates in which activity had been blocked with a TTX cuff. In control endplates, there was good correlation between MEPC decay and EPC decay (Fig. 2A) (slope, $0.70 ; r=0.76 ; p<0.01$ ). After block of synaptic activity, the correlation was reduced (Fig. $2 A$ ) (slope, $2.72 ; r=0.51 ; p<$ 0.01 ). Endplates in which activity had been blocked had prolonged EPC decay times relative to control endplates with the same MEPC decay times. This suggests that EPC decay prolongation occurs, to a large degree, independently of the minor prolongation of MEPC decay.

Prolongation of EPC decay may have either a presynaptic or a postsynaptic cause. One possible cause of prolonged EPC decay that would not prolong MEPC decay is a presynaptic change that 


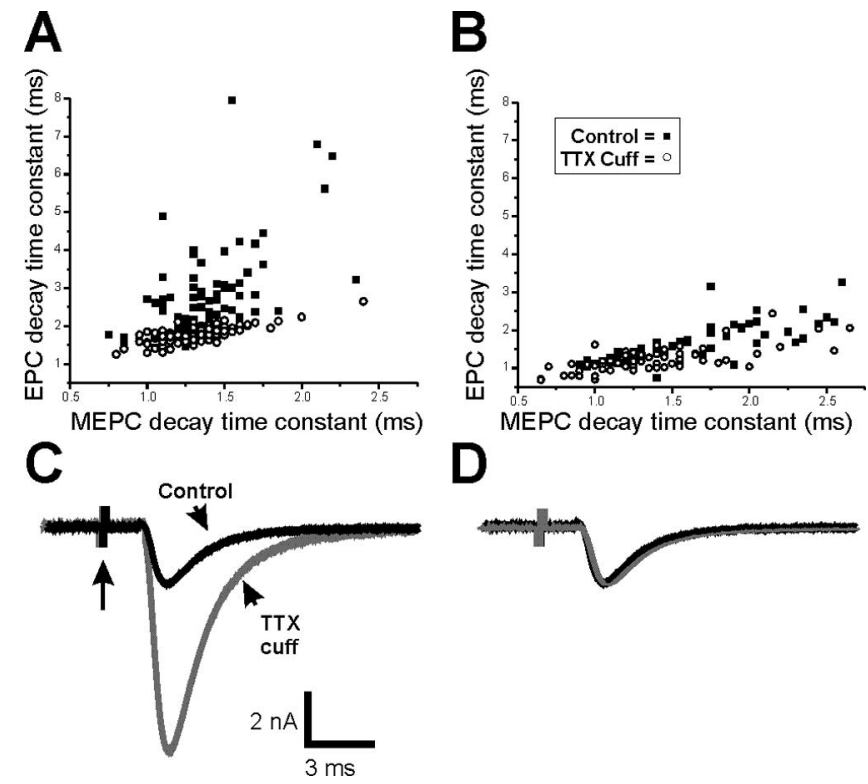

Figure 2. The close relationship between EPC decay time constant and MEPC decay time constant is lost after block of synaptic activity but is regained in solution containing low calcium. $\boldsymbol{A}$, Scatter plot of EPC decay time constant versus MEPC decay time constant for control endplates (open circles) and endplates after block of activity with a TTX cuff (filled squares). EPC and MEPC recordings were obtained in Ringer's solution containing normal extracellular calcium. There is marked prolongation of EPC decay time constant after blocking activity in endplates that had no prolongation of MEPC decay time constant. $\boldsymbol{B}$, Scatter plot of EPC decay time constant versus MEPC decay time constant in Ringer's solution containing low extracellular calcium for control endplates and endplates after block of activity with a TTX cuff. The data from endplates in which activity was blocked essentially overlaps data from control endplates. $\boldsymbol{C}$ Superimposed EPCs recorded in solution containing low calcium from a control endplate (black) and an endplate in which synaptic activity was blocked by a TTX cuff for $8 \mathrm{~d}$ (gray). Although the peak amplitude of the EPC recorded in low calcium is larger after block of activity (Wang et al., 2004), there is little difference in the rate of EPC decay. Each EPC is preceded by a stimulus artifact (arrow). Note the difference in vertical scale relative to Figure 1A.D, The superimposed, normalized EPCs shown in $\boldsymbol{C}$.

extends vesicle release after presynaptic action potentials. If the presynaptic change was prolongation of the calcium elevation that triggers release, lowering external calcium might reverse the prolongation. When we recorded in Ringer's solution containing low calcium and high magnesium ( $1 \mathrm{~mm}$ and $8 \mathrm{~mm}$, respectively), quantal content was reduced to an average of $3.3 \pm 0.7(n=4$ muscles) in control endplates and $6.7 \pm 0.7$ ( $n=4$ muscles) in activity-blocked endplates, as reported previously $(p<0.01)$ (Wang et al., 2004). The difference in quantal content as well as an increase in quantal size after application of a TTX cuff (Wang et al., 2005) resulted in a significant increase in EPC amplitude in TTX-cuff preparations relative to control (Fig. 2C) (Wang et al., 2004). Despite the difference in EPC amplitude, when we plotted EPC decay versus MEPC decay for both control and activityblocked endplates in low-calcium Ringer's solution, there was extensive overlap (Fig. 2 B). This is in contrast to the plot of EPC decay versus MEPC decay that follows the block of activity in Ringer's solution containing normal calcium (Fig. $2 \mathrm{~A}$ ). In lowcalcium Ringer's solution, the mean MEPC decay time constant was $1.34 \pm 0.07 \mathrm{~ms}$ in control and $1.49 \pm 0.05 \mathrm{~ms}$ in activityblocked endplates $(p=0.12)$. EPC decay was $1.23 \pm 0.07 \mathrm{~ms}$ in control and $1.55 \pm 0.03 \mathrm{~ms}$ in activity-blocked endplates $(p<$ 0.01 ) (Fig. 2D). The difference in EPC decay time constants $(0.32$ ms) was only slightly greater than the difference in MEPC decay time constants $(0.15 \mathrm{~ms})$. Thus, prolongation of EPC decay, be-

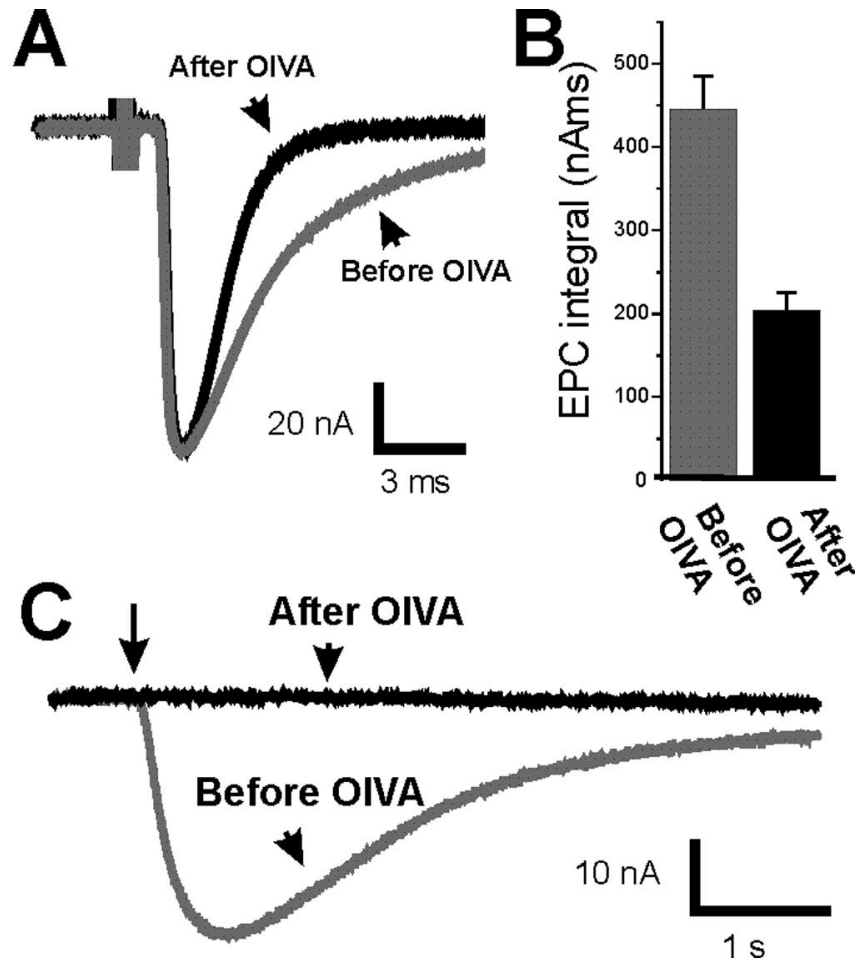

Figure 3. Prolongation of EPCs after activity blockade is reversed by a toxin against the fetal-type AChR. $A$, EPC from an endplate in which synaptic activity was blocked for $8 \mathrm{~d}$ (gray) and from the same endplate after application of $\alpha A$-conotoxin OIVA[K15N] to inhibit fetal-type AChRs (black). B, Mean EPC integral of activity-blocked endplates before (gray) and after (black) application of $\alpha$ A-conotoxin OIVA[K15N]. In endplates in which activity was blocked, application of $\alpha$ A-conotoxin OIVA[K15N] caused a significant reduction in EPC integral $(p<0.01)$. $n=6$ muscle fibers. Error bars represent the SEM. $C$, The response to extrajunctional application of ACh for a muscle fiber in which synaptic activity has been blocked for $8 \mathrm{~d}$ (gray) and the same fiber after application of $\alpha \mathrm{A}$-conotoxin OIVA[K15N] to inhibit fetal-type AChRs (black). The extrajunctional response to ACh was completely blocked in all five fibers studied $(p<0.01)$. The arrow indicates the beginning of a $100 \mathrm{~ms}$ pulse of ACh onto the muscle fiber.

yond that of the MEPC decay, was reversed when quantal content was lowered.

The finding that MEPC decay was less prolonged than EPC decay, as well as the finding that lowering external calcium reversed EPC prolongation, suggested that the cause of EPC prolongation was an extended period of release after a presynaptic action potential. However, another possible cause of EPC prolongation after block of synaptic activity is postsynaptic upregulation of fetal-type AChRs (Kues et al., 1995), which have a longer mean open time (Sakmann and Brenner, 1978; Fischbach and Schuetze, 1980). To examine the contribution of fetal-type AChRs to prolongation of EPC decay, we selectively blocked fetal-type AChRs using a recently discovered toxin that is selective for fetal-type AChRs ( $\alpha \mathrm{A}$-conotoxin OIVA[K15N]) (Teichert et al., 2005, 2006). Before using $\alpha \mathrm{A}$-conotoxin OIVA $[\mathrm{K} 15 \mathrm{~N}]$ on muscle after blockade of synaptic activity, we confirmed that it had no effect on control muscle. As expected, in control endplates, $\alpha \mathrm{A}$-conotoxin OIVA[K15N] had no effect on EPCs or MEPCs (Table 1). In contrast, in endplates after an extended block of synaptic activity using a TTX cuff, $\alpha \mathrm{A}$-conotoxin OIVA $[\mathrm{K} 15 \mathrm{~N}]$ reversed the prolongation of EPC decay and the increase in EPC integral (Fig. $3 A, B$; Table 1). The shortening of EPC decay was accompanied by shortening of MEPC decay without a statistically significant reduction in EPC amplitude (Table 1) $(p=0.18)$ or MEPC amplitude $(1.71 \pm 0.10 \mathrm{nA}$ before vs 


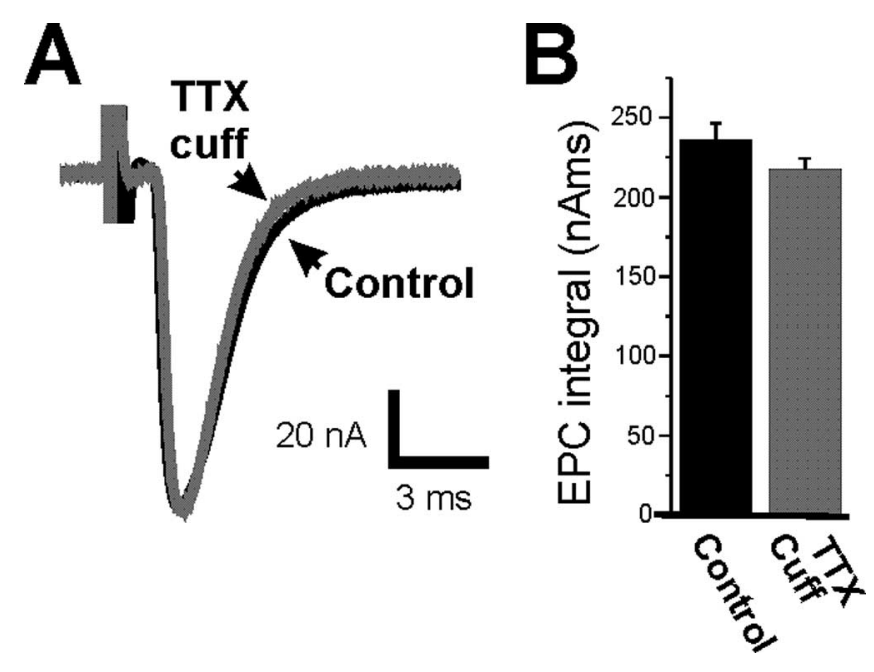

Figure 4. Prolongation of EPC decay does not occur in $\mathrm{CIC}-1$ chloride channel null mice that do not upregulate fetal-type AChRs. $A$, Superimposed EPCs from an active CIC endplate (black) and a $\mathrm{CIC}$ endplate in which synaptic activity was blocked for $8 \mathrm{~d}$ (gray). $\boldsymbol{B}$, Mean EPC integral in active CIC endplates (black) and CIC endplates in which synaptic activity was blocked for 7-10 d (gray). There is no statistically significant difference in EPC integral after block of synaptic activity in $\mathrm{CIC}$ endplates $(p=0.17) . n=7$ muscles for both active $\mathrm{CIC}$ endplates and $\mathrm{CIC}$ endplates in which nerve activity was blocked. Error bars represent the SEM.

$1.60 \pm 0.06 \mathrm{nA}$ after; $p=0.31)$. To confirm that $\alpha \mathrm{A}$-conotoxin OIVA[K15N] was blocking fetal-type AChRs, we examined its effect on extrajunctional sensitivity to applied ACh, which is thought to be mediated exclusively by fetal-type AChRs (Kues et al., 1995). We found that $\alpha \mathrm{A}$-conotoxin OIVA[K15N] completely blocked extrajunctional sensitivity to applied ACh in the five fibers studied (Fig. 3C). These data suggest that postsynaptic upregulation of fetal-type AChRs underlies the prolongation of both EPC and MEPC decay.

Because $\alpha$ A-conotoxin OIVA $[\mathrm{K} 15 \mathrm{~N}]$ could have an unknown presynaptic effect that reverses prolongation of EPC decay after an extended block of synaptic activity, we tested the role of upregulation of fetal-type AChRs in prolongation of EPC decay in an additional way. We blocked synaptic activity with a TTX cuff in ClC-1 chloride channel null mice (Klocke et al., 1994) in which there is no upregulation of fetal-type AChRs. In ClC mice, muscle is hyperexcitable (Steinmeyer et al., 1991; Gronemeier et al., 1994) and remains active after loss of nerve activity (Wang et al., 2005). The continued muscle activity in ClC muscle prevents upregulation of extrajunctional AChRs (Wang et al., 2005). Because all extrajunctional AChRs are fetal type (Fig. $3 C$ ), this suggests that upregulation of fetal-type AChRs is prevented in $\mathrm{ClC}$ mice.

In $\mathrm{ClC}$ mice, nerve excitability is normal so placement of a TTX cuff causes the same block of presynaptic nerve activity as in control mice. If prolongation of EPC decay is caused by prolonged presynaptic release of vesicles that is triggered by loss of presynaptic action potentials, prolongation of EPC decay should occur in $\mathrm{ClC}$ mice despite the absence of upregulation of postsynaptic fetal-type AChRs. In ClC endplates, an extended block of nerve activity triggered no increase in EPC integral (Fig. $4 B$, Table 1 ) ( $p=0.20)$, no prolongation of EPC decay (Fig. $4 A$, Table 1) $(p=0.66)$, and no prolongation of MEPC decay (Table 1$)$ $(p=0.89)$. The data from $\mathrm{ClC}$ mice together with the data using $\alpha \mathrm{A}$-conotoxin OIVA $[\mathrm{K} 15 \mathrm{~N}]$ indicate that upregulation of fetaltype AChRs is responsible for the prolongation of both EPC and MEPC decay after prolonged block of synaptic activity.

\section{Discussion}

We found that an extended block of synaptic activity, using a TTX cuff at the NMJ in vivo, triggered prolongation of EPC decay that was accompanied by only modest prolongation of MEPC decay. Prolongation of EPC decay was reversed when extracellular calcium was lowered. Selective inhibition of fetal-type AChRs reversed EPC prolongation, which suggests the prolongation depends on activation of fetal-type AChRs. Furthermore, there was no prolongation of EPC decay in transgenic mice that do not upregulate fetal-type AChRs after an extended block of synaptic activity. Surprisingly, our data indicate that selective prolongation of EPC decay is not presynaptic in origin but it is instead attributable to upregulation of fetal-type AChRs.

There are several potential causes of prolongation of EPC decay. One is reduction in activity of acetylcholinesterase (AChE), a second is presynaptic prolongation of vesicle release, and a third is postsynaptic changes in AChRs. We previously found that inhibition of AChE caused marked prolongation of MEPC decay (Wang et al., 2005). Because we found that prolonged block of synaptic activity caused only minimal prolongation of MEPC decay, reduction in AChE activity cannot account for prolongation of EPC decay. If prolongation of presynaptic vesicle release underlies prolongation of EPC decay, MEPC decay will not be prolonged in parallel with EPC decay. When we examined the correlation between prolongation of MEPC decay and EPC decay, we found that MEPC decay did not account for prolongation of EPC decay. This led us to suspect that prolonged presynaptic release of vesicles caused prolongation of EPC decay.

One way in which vesicle release might be prolonged is if there is prolongation of the presynaptic calcium signal that triggers fusion of vesicles after an action potential. If this were the case, lowering external calcium might reverse prolongation of EPC decay. We lowered external calcium and reversed the prolongation of EPC decay, supporting the idea that the cause was presynaptic. We were thus surprised when application of $\alpha \mathrm{A}$-conotoxin OIVA[K15N], and experiments in ClC-1 null mice demonstrated that upregulation of fetal-type AChRs caused the prolongation of EPC decay. How could this be?

In muscle paralyzed by block of nerve activity, upregulation of fetal-type AChRs occurs in extrajunctional muscle regions, whereas adult AChRs continue to be expressed exclusively at muscle endplate nuclei (Kues et al., 1995). Thus, after block of nerve activity, the majority of AChRs within endplates is adult type, whereas the majority of extrasynaptic AChRs is fetal type. Consistent with this, we found that after blocking nerve activity, blocking fetal-type AChRs with $\alpha$ A-conotoxin OIVA[K15N] did not significantly reduce EPC amplitude but completely blocked extrajunctional sensitivity to applied ACh. Given the distribution of adult-type and fetal-type AChRs after blocking activity, we interpret our data on EPC and MEPC decay after blocking activity in the following manner: during MEPCs, the majority of released ACh binds to adult-type AChRs located within the endplate. Adult-type AChRs have relatively short open times (Sakmann and Brenner, 1978; Fischbach and Schuetze, 1980) and are near high concentrations of AChE, so MEPCs decay rapidly. During large EPCs, however, ACh escapes from endplates, diffuses over the extrajunctional muscle membrane, and binds fetaltype AChRs. Fetal-type AChRs have longer open times (Sakmann and Brenner, 1978; Fischbach and Schuetze, 1980), and there is no extrajunctional AChE to eliminate ACh, so EPCs decay slowly. In this interpretation of the data, we classified AChRs as either being within the endplate or being extrajunctional. However, 
another interpretation is possible. Normally, AChRs are localized to the crests of the secondary folds within the postsynaptic membrane of the endplate (Fertuck and Salpeter, 1976). If, after blocking synaptic activity, fetal-type AChRs are expressed within the depths of the secondary folds, ACh might diffuse into the depths of the folds during large EPCs to bind fetal-type AChRs and prolong EPC decay.

Lowering external calcium reduced quantal content and reversed prolongation of EPC decay. This implies that ACh escapes from the endplate only when a large number of vesicles fuse simultaneously. The escape of ACh during large EPCs would explain how upregulation of extrajunctional fetal-type AChRs prolongs EPC decay to a greater degree than MEPC decay. We hypothesize that during EPCs, AChE becomes saturated and ACh escapes from endplates, binds to extrajunctional fetal-type AchRs, and prolongs EPCs. During MEPCs, AChE does not become saturated, so no ACh escapes and MEPC decay is not prolonged.

Our data suggest that when extrajunctional AChRs are present, spillover of ACh can be detected. However, at normal NMJs there are no extrajunctional AChRs, so there is no way of knowing whether spillover of ACh occurs. If spillover occurs at normal NMJs, it could participate in signaling to Schwann cells through muscarinic AChRs on Schwann cells (Colomar and Robitaille, 2004).

Previous studies have demonstrated homeostatic increases in spontaneous miniature EPSC (MEPSC) amplitude after an extended block of activity at neuronal synapses. The increase in MEPSC amplitude was paralleled by upregulation of postsynaptic neurotransmitter receptors (O'Brien et al., 1998; Turrigiano et al., 1998; Wierenga et al., 2005). This finding led to the hypothesis that upregulation of postsynaptic receptors underlies the increase in MEPSC amplitude. At the NMJ after an extended block of activity, there is also an increase in MEPC amplitude (Wang et al., 2005 ) that is paralleled by a dramatic upregulation of postsynaptic AChRs (Hartzell and Fambrough, 1972; Lomo and Rosenthal, 1972). Based on these findings, it is tempting to assume that upregulation of postsynaptic AChRs after blocking synaptic activity is the mechanism underlying increased MEPC amplitude. However, within the endplate, there is no increase in AChR density after blocking synaptic activity (Wang et al., 2005). This suggests that the locus of upregulation of MEPC amplitude is presynaptic. Our finding that blocking fetal-type AChRs did not reduce MEPC amplitude after a block of activity is further evidence that although upregulation of AChRs parallels upregulation of MEPC amplitude at the NMJ, upregulation of AChRs is not the mechanism underlying increased MEPC amplitude.

Our data are the first to show a physiological function for upregulation of extrajunctional AChRs. Normally, there is a large safety factor for synaptic transmission at the NMJ, so increasing synaptic current will have little functional impact. Early in reinnervation, however, the safety factor is low. The effect of extrajunctional fetal-type AChRs on synaptic function that we report here may have implications for synaptic transmission early in reinnervation when the safety factor is low. Denervated muscle has high levels of extrajunctional AChRs (Hartzell and Fambrough, 1972; Lomo and Rosenthal, 1972; Lomo and Westgaard, 1975), and at early times during reinnervation of muscle, there is prolongation of EPC decay (Argentieri et al., 1992). Given our findings, it appears likely that prolongation of EPCs after reinnervation is attributable to the presence of extrajunctional AChRs. Because EPCs are small early in the course of reinnervation (Argentieri et al., 1992), prolongation of synaptic current because of extrajunctional AChRs could be important in reaching threshold for muscle fiber activation.

\section{References}

Argentieri TM, Aiken SP, Laxminarayan S, McArdle JJ (1992) Characteristics of synaptic transmission in reinnervating rat skeletal muscle. Pflügers Arch 421:256-261.

Colomar A, Robitaille R (2004) Glial modulation of synaptic transmission at the neuromuscular junction. Glia 47:284-289.

Davis GW (2006) Homeostatic control of neural activity: from phenomenology to molecular design. Annu Rev Neurosci 29:307-323.

Fertuck HC, Salpeter MM (1976) Quantitation of junctional and extrajunctional acetylcholine receptors by electron microscope autoradiography after 125I- $\alpha$-bungarotoxin binding at mouse neuromuscular junctions. J Cell Biol 69:144-158.

Fischbach GD, Schuetze SM (1980) A post-natal decrease in acetylcholine channel open time at rat end-plates. J Physiol (Lond) 303:125-137.

Glavinovic MI (1979) Voltage clamping of unparalysed cut rat diaphragm for study of transmitter release. J Physiol (Lond) 290:467-480.

Gronemeier M, Condie A, Prosser J, Steinmeyer K, Jentsch TJ, Jockusch H (1994) Nonsense and missense mutations in the muscular chloride channel gene Clc-1 of myotonic mice. J Biol Chem 269:5963-5967.

Hartzell HC, Fambrough DM (1972) Acetylcholine receptors. Distribution and extrajunctional density in rat diaphragm after denervation correlated with acetylcholine sensitivity. J Gen Physiol 60:248-262.

Klocke R, Steinmeyer K, Jentsch TJ, Jockusch H (1994) Role of innervation, excitability, and myogenic factors in the expression of the muscular chloride channel ClC-1. A study on normal and myotonic muscle. J Biol Chem 269:27635-27639.

Kues WA, Brenner HR, Sakmann B, Witzemann V (1995) Local neurotrophic repression of gene transcripts encoding fetal AChRs at rat neuromuscular synapses. J Cell Biol 130:949-957.

Lomo T, Rosenthal J (1972) Control of ACh sensitivity by muscle activity in the rat. J Physiol (Lond) 221:493-513.

Lomo T, Westgaard RH (1975) Further studies on the control of ACh sensitivity by muscle activity in the rat. J Physiol (Lond) 252:603-626.

Magrassi L, Purves D, Lichtman JW (1987) Fluorescent probes that stain living nerve terminals. J Neurosci 7:1207-1214.

Neter J, Wasserman W, Kutner MH (1990) Applied linear statistical models. Boston: Richard D. Irwin.

O’Brien RJ, Kamboj S, Ehlers MD, Rosen KR, Fischbach GD, Huganir RL (1998) Activity-dependent modulation of synaptic AMPA receptor accumulation. Neuron 21:1067-1078.

Sakmann B, Brenner HR (1978) Change in synaptic channel gating during neuromuscular development. Nature 276:401-402.

Steinbach JH (1989) Structural and functional diversity in vertebrate skeletal muscle nicotinic acetylcholine receptors. Annu Rev Physiol 51:353-365.

Steinmeyer K, Klocke R, Ortland C, Gronemeier M, Jockusch H, Grunder S, Jentsch TJ (1991) Inactivation of muscle chloride channel by transposon insertion in myotonic mice. Nature 354:304-308.

Teichert RW, Rivier J, Torres J, Dykert J, Miller C, Olivera BM (2005) A uniquely selective inhibitor of the mammalian fetal neuromuscular nicotinic acetylcholine receptor. J Neurosci 25:732-736.

Teichert RW, Lopez-Vera E, Gulyas J, Watkins M, Rivier J, Olivera BM (2006) Definition and characterization of the short $\alpha$ A-conotoxins: a single residue determines dissociation kinetics from the fetal muscle nicotinic acetylcholine receptor. Biochemistry 45:1304-1312.

Turrigiano GG, Nelson SB (2004) Homeostatic plasticity in the developing nervous system. Nat Rev Neurosci 5:97-107.

Turrigiano GG, Leslie KR, Desai NS, Rutherford LC, Nelson SB (1998) Activity-dependent scaling of quantal amplitude in neocortical neurons. Nature 391:892-896.

Wang X, Engisch KL, Li Y, Pinter MJ, Cope TC, Rich MM (2004) Decreased synaptic activity shifts the calcium dependence of release at the mammalian neuromuscular junction in vivo. J Neurosci 24:10687-10692.

Wang X, Li Y, Engisch KL, Nakanishi ST, Dodson SE, Miller GW, Cope TC, Pinter MJ, Rich MM (2005) Activity-dependent presynaptic regulation of quantal size at the mammalian neuromuscular junction in vivo. J Neurosci 25:343-351.

Wierenga CJ, Ibata K, Turrigiano GG (2005) Postsynaptic expression of homeostatic plasticity at neocortical synapses. J Neurosci 25:2895-2905.

Witzemann V, Barg B, Nishikawa Y, Sakmann B, Numa S (1987) Differential regulation of muscle acetylcholine receptor gamma- and epsilonsubunit mRNAs. FEBS Lett 223:104-112. 